\title{
STRUCTURAL ASSESSMENT OF CULTURAL HERITAGE BUILDINGS USING HBIM AND VIBRATION-BASED SYSTEM IDENTIFICATION
}

\author{
ALFREDO CALİ ${ }^{1 *}$, ANTONELLA SAISI ${ }^{1}$ AND CARMELO GENTILE ${ }^{1}$ \\ ${ }^{1}$ Department of Architecture, Built environment and Construction engineering (DABC) \\ Politecnico di Milano, Milan, Italy \\ Piazza Leonardo da Vinci, 32 - 20133 Milan, Italy \\ e-mail: \{alfredo.cali, antonella.saisi, carmelo.gentile\}@polimi.it (*corresponding author)
}

Keywords: Historical Structure, Masonry, Monitoring, Non-Destructive Inspection

\begin{abstract}
The paper exemplifies the application of the methodology involving historic and architectural research complemented by HBIM and operational modal testing in the structural modelling of a heritage palace, the Galleria degli Antichi in the historic town of Sabbioneta (Italy), included in the UNESCO World Heritage list since 2008. This monumental building was built in the 16th century. Full details on the history of the building and the information obtained in the nondestructive survey are given in the paper. The good knowledge of the structural geometry, along with the complete inspection carried out and the large number of identified vibration modes, allowed to establish a numerical model of the monumental building for a first quantitative assessment of its structural condition.
\end{abstract}

\section{INTRODUCTION}

The structural analysis of historic masonry structures is a complex task, involving the collection of data from a wide range of sources and the subsequent merging process. Research underlines the significance of an accurate planning of such activities in order to get reliable information about the structural characteristics supporting the structural modeling [1].

Starting from [2] to more recent versions, the Italian Seismic Code bases the structural modeling and the seismic assessment on such multi-cultural approach. The novelty and the importance of such a methodology was assumed and reaffirmed by the ISCARSAH - ICOMOS Committee in a general document concerning the analysis and the structural restoration of architectural heritage [3]. Therefore, the structural modeling requires a process involving historic research, geometric survey, direct inspection supplemented by tests on sampled materials and local non-destructive and minor-destructive tests. The methodology highly recommends the monitoring of the recognized structural pathologies [1].

The structural analysis of historic masonry building is commonly performed in the elastic range (see e.g. [4]) due to the high level of uncertainties about the non-linear properties of the materials. Nevertheless, even linear elastic analysis might be affected by uncertainties and lack of information. Dynamic tests in operational conditions provide quantitative parameters (i.e., resonant frequencies, mode shapes and damping ratios), which are representative of the structural condition and remarkably contribute to the knowledge of the building and to the model calibration and validation [5-6]. In addition, ambient vibration tests are especially suitable to historic buildings for the fully non-destructive way of testing, that is a priority for 
the architectural heritage.

It is further recalled that various software codes nowadays implement the Building Information Modeling (BIM) methodology (see e.g. [7]), which describes collaborative processes for production and management of structured electronic information. BIM is generally aimed at creating interactive database collectors for the elaboration of architectural projects, including structural characteristics. Similarly, the information collected in the assessment of historic buildings might be summarized through the creation of a Heritage Building Information Model (H-BIM) [8-9].

Current studies on H-BIM are mainly aimed at improving the geometric description of the "as-built" configuration of heritage buildings through geomatic survey (i.e., laser scanning and photogrammetry) and the organization of the data sources, whereas only few examples are available in the literature on the use of H-BIM in combination with Finite Element (FE) analysis [10]. In [11], the H-BIM potential role in the structural analysis and decision making for restoration and rehabilitation proposals is also pointed out. Furthermore, the integration between BIM, diagnostics and monitoring is suggested in [12], with the discussion including dynamic testing and FE analysis to assess the structural health condition.

In the present paper, a H-BIM workflow was developed to improve the knowledge of an important historical palace; the workflow has been established to manage and merge the information collected through documentary research, geometric survey and description, direct inspection, FE modeling, operational modal testing and analysis. The historic building named Galleria degli Antichi[13-14] in Sabbioneta (Italy) was selected to demonstrate the adopted

multidisciplinary work

(1) Information acqu

(2) Data manageme

(3) Transfer of infor
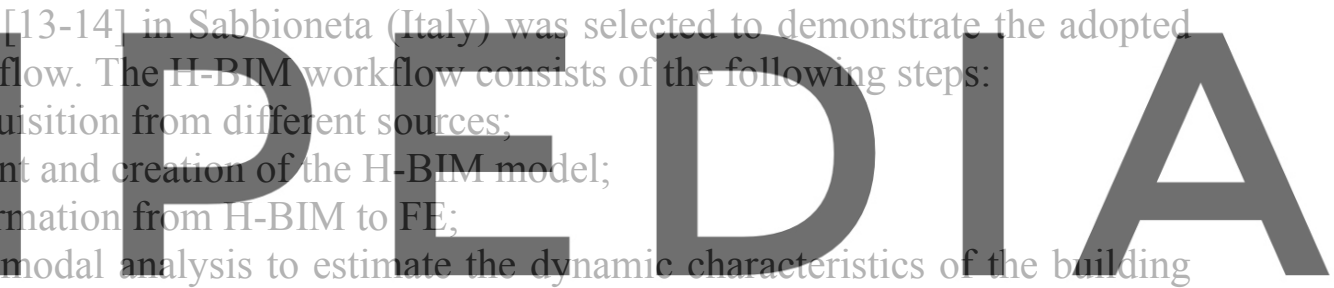

and design of (ambient) vibration testing;

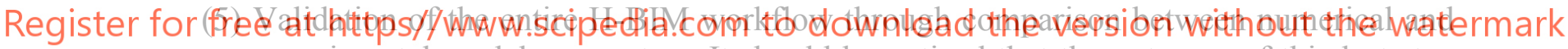
experimental modal parameters. It should be noticed that the outcome of this last step might be considered as positive when one-to-one correlation exists between numerical and experimental mode shapes with limited discrepancy between natural frequencies. Of course, correlation between operational modal analysis (OMA) and Finite Element analysis (FEA) might be further improved through model updating procedures [5-6].

\section{H-BIM FOR STRUCTURAL ASSESSMENT: THE GALLERIA DEGLI ANTICHI}

The presented H-BIM workflow was applied to the Galleria degli Antichi in Sabbioneta, Italy. This impressive building, with the main dimension of almost $100 \mathrm{~m}$, was built in the $16^{\text {th }}$ century. On site inspections and tests carried out by the authors, along with the processing of existing geometric surveys [13-14], allowed to define the main characteristics of the heritage building and the subsequent implementation within the H-BIM framework.

\subsection{Historic and documentary research}

The analysis of several historic documents was the first step of the building investigation [13-14]. Documentary research was carried out in several archives, collecting documents aimed 
at pointing out the evolution of the buildings in the 20th century as well as the sequence of interventions and changes of use [14].

The town of Sabbioneta, included in the UNESCO World Heritage list in 2008, was built by Vespasiano Gonzaga in the 16th century to establish the capital of his duchy. In about 35 years, the traces of the ancient settlements were transformed into a fortified Ideal City, recognized as one of the higher examples of the Renaissance principles in urban planning. The Galleria degli Antichi (Fig. 1), probably designed by Giuseppe Dattaro and built between 1583 and 1584 to host the art collection of the Duke, was one of the several palaces of the capital. The Galleria degli Antichi is connected through a flyover passage (Fig. 1f) to a former building named Palazzo Giardino. At present, the flyover is the only access to the building so that visitors have to cross the ground and first floor of the Palazzo Giardino, to reach the first floor of the Galleria degli Antichi [13-14].
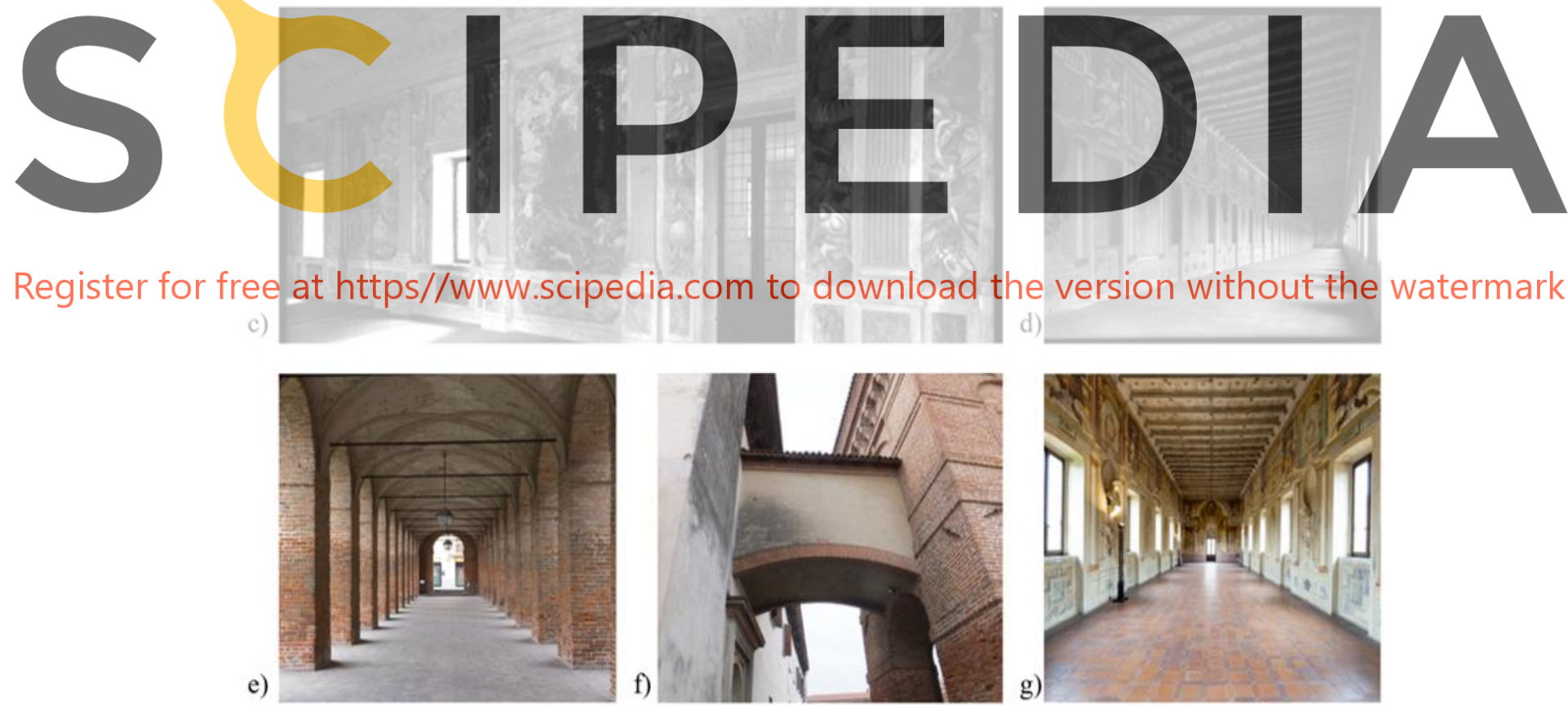

Register for free at https//www.scipedia.com to
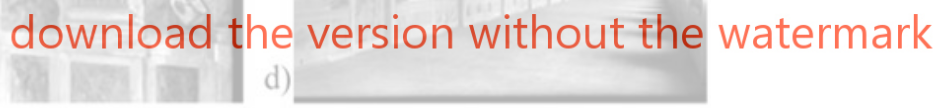

e)
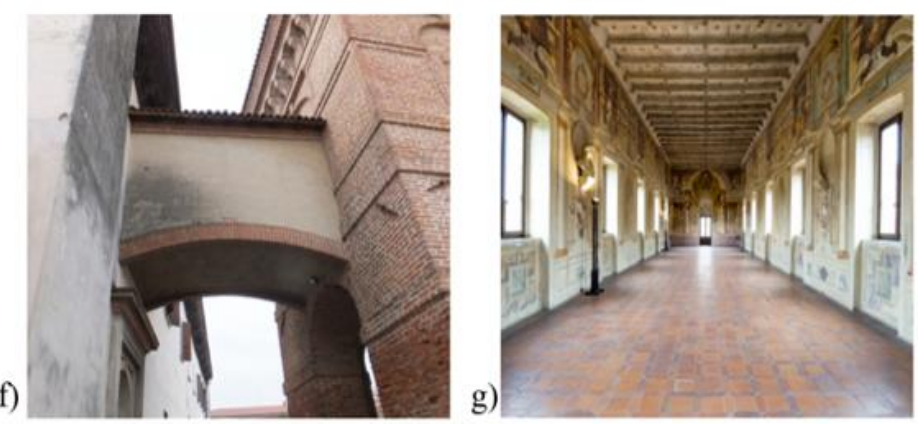

Figure 1. Historic (a) and current (b) views of Galleria degli Antichi and Palazzo Giardino. Historic (c-d) and current (e-g) views of different parts of Galleria degli Antichi.

The Galleria degli Antichi is characterized by a long open arcade at the ground floor with 27 couple of massive squared columns made by brick masonry (Fig. 1e) supporting crossvaults. The structure of the gallery is made by brick masonry (Figs. 1a, $1 \mathrm{~b}$ and 1e). At the first floor, the building has a long gallery with 26 windows each side (Fig. 1). The gallery walls were 
frescoed and stuccoed in a very refined way by famous painters and craftsman of the time (Figs. $1 \mathrm{c}, 1 \mathrm{~d}$ and $1 \mathrm{~g}$ ) [13-14]. The gallery is covered by wooden lacunar ceiling with panels richly decorated but apparently in a low state of preservation (Fig. 1g).

The construction is currently used as a museum, but the evidence of several changes of function has been found in the archives [14]. For example, in 1927 troops billeted in the palaces as previously happened with the Napoleon Army (1806). In 1928, the building hosted the offices and the meeting rooms of the fascist party. In 1947 some halls at the ground floor of Palazzo Giardino were used as food shop with a kitchen and in 1948 an organization - involved in social, cultural and free-time activities for the workers - rent some rooms. In 1975 and 1990 Palazzo Giardino and Galleria degli Antichi hosted the antique market.

The archive research also documents several repair interventions, which systematically followed each misuse of the building. The restorations concerned mainly the surfaces, the frescoes and the stuccos [14]. Similarly, other interventions were carried out in 1935, 1953, $1966,1989,2001$ to repair the effect of the water leakage due to the roof damage. Metal ties restraining the crossing vaults were probably inserted during the works carried out in 1950. Substantial interventions to the structure were performed in 1952, including the rebuilding of the flyover passage. The descriptions of the damages and of the interventions in the archive records are in general very accurate, documenting the presence of cracks, as well. This last information is very important in order to define the real entity of the damage caused by the 2012 earthquake [13-14]. Furthermore, the available historical pictures (Fig. 1) are of utmost importance to identify damage, as well as the transformations occurred to the buildings.

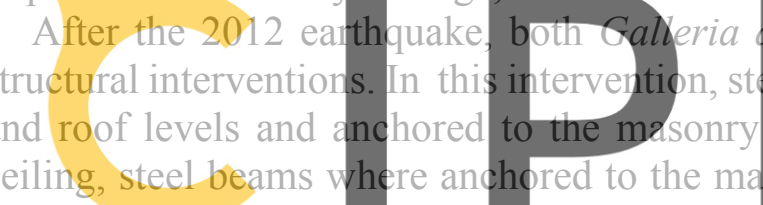

system of diagonal and transversal steel ties.
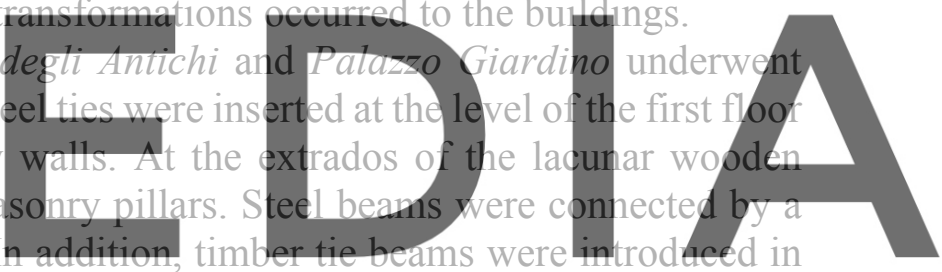

such anchoring system, probably to distribute the axial compressive stresses.

Register for free at https//www.scipedia.com to download the version without the watermark 2.2 On site inspection and geometric survey

On site inspection is carried out to collect data on the as-built state of the heritage construction. Thematic surveys resumes the information according to the specific research objectives (i.e., the surface materials with their decay, the crack pattern or the connection type between the structural elements, etc.). Careful and systematic comparison between the information gathered from archive documents with the visual inspection of the building surface improves the knowledge of the current state of heritage buildings $[1,13]$.

A relevant complementary activity is the geometric survey, particularly when ortho-pictures of the fronts are available. Furthermore, geometric surveys could be carried out by photogrammetry and laser scanning reconstructions.

The survey of Galleria degli Antichi was carried out by HE.SU.Tech Politecnico di Milano, Campus of Mantua. The point cloud, developed using Autodesk Recap ${ }^{\circledR}$ software, was obtained with the Laser Scanner and Theodolite tools. The processed file was imported in AutoCAD, where vector drawings were extracted and saved in DWG format (Fig. 2). 
(a)

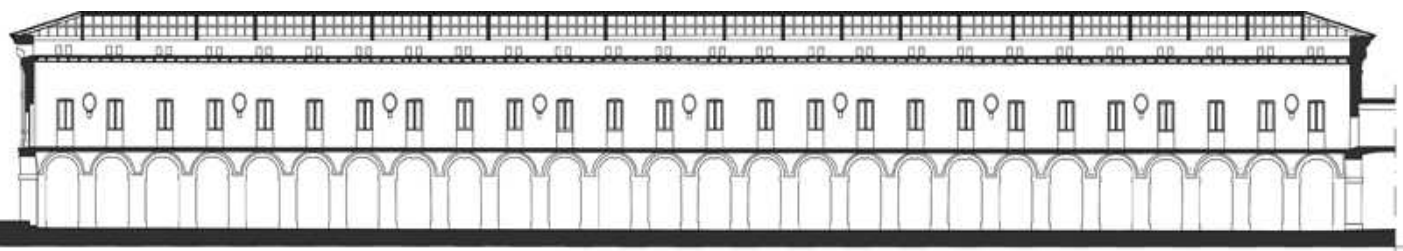

(b)

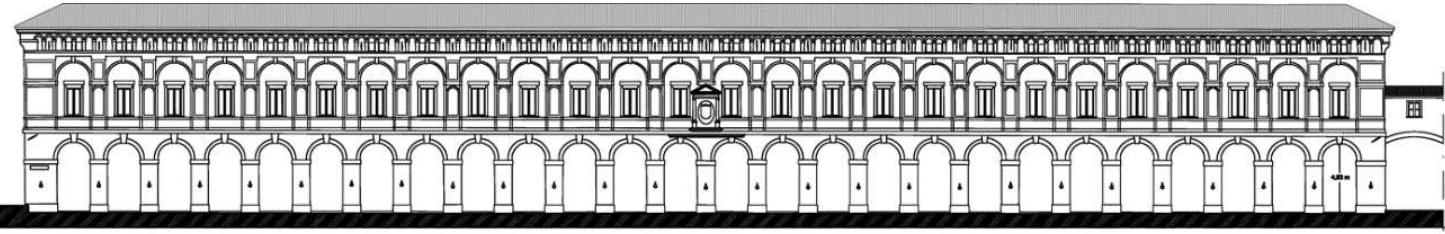

(c)

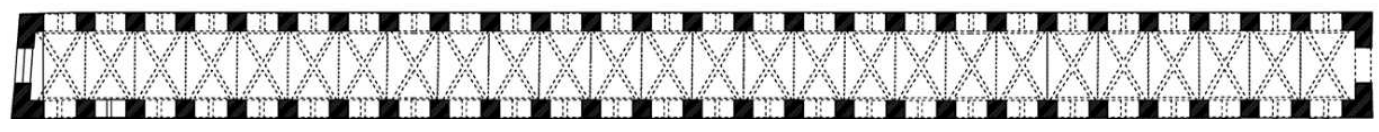

Figure 2. Galleria degli Antichi: (a) Longitudinal section; (b) West front; (c) Plan of the ground floor [14].

(a)

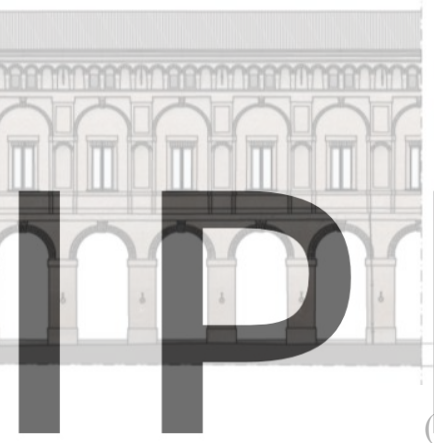

(b)

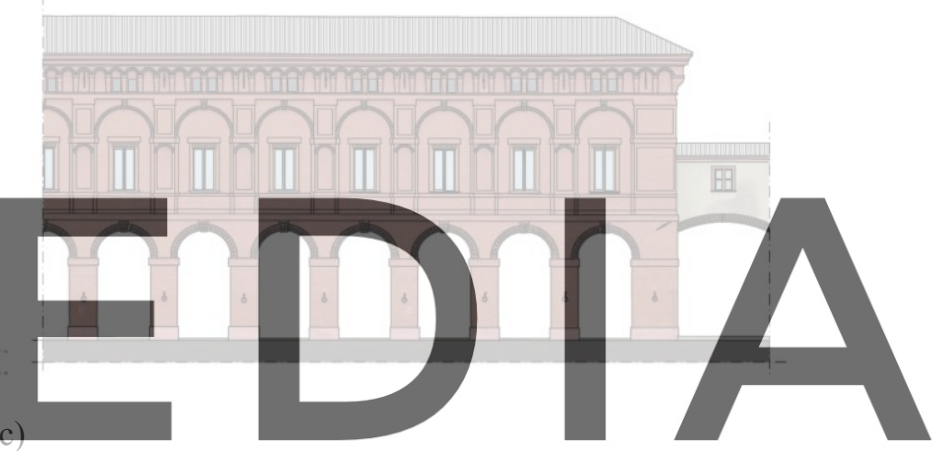

Register for free at https//www.scipedia.com to download the version without the watermark

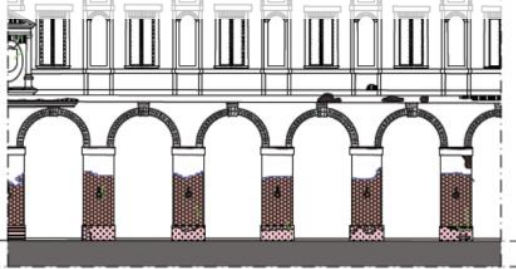

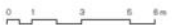

Figure 3. Galleria degli Antichi: (a) Geometric survey; (b) Material survey and (c) Material decay survey [14].

Such DWG files represent the summary of geometric survey, which is the base source upon the information collected by comparing the archive documents with on inspections of the buildings. Geometric and thematic surveys have a primary importance in buildings because it helps resuming the investigation carried out in the construction [1] (Fig. 3). Most of the decay problems of the façade of the investigated building are caused by the rising damp: Fig. 2c describes the height of the dampness level and the typical decay of masonry. In the interior of 
the building, traces of surface decay are explicable mainly to past leakages occurred from the damaged roof. The water leakage from the roof damaged the ceiling structure as well. Furthermore, during heavy rain the water leaks from the windows of the building, damaging the decoration.

\subsection{Historic building information modelling}

The previous steps of historical research, geometric and material survey, decay survey and the on site investigation allow defining the main characteristic of the heritage building. The collected information are imported, represented and summarized in the H-BIM model. Although H-BIM can be developed from point clouds, the authors preferred to use the 2D DWG files since the availability of technical 2D drawings is currently more common.

In the model, the building consists of 3D objects (walls, openings, beams, etc.) and those 3D objects are used as database for the information management. The objects collect data about physical and mechanical characteristics of the material, structural connections, boundary conditions and loads; updating of the object characteristics is possible when new information are acquired, without a time-consuming effort during the modification process. Furthermore, each object is defined and dated according to the constructive phase evolution obtained from the historic research.

After the H-BIM model has been completed, the appropriate selection of structural elements allows to define an intermediate "analytical model" (containing all the relevant geometric and structural information

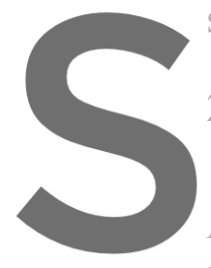

2.4 From H-BIM to

In the present application, Analysis ${ }^{\circledR}$ software [
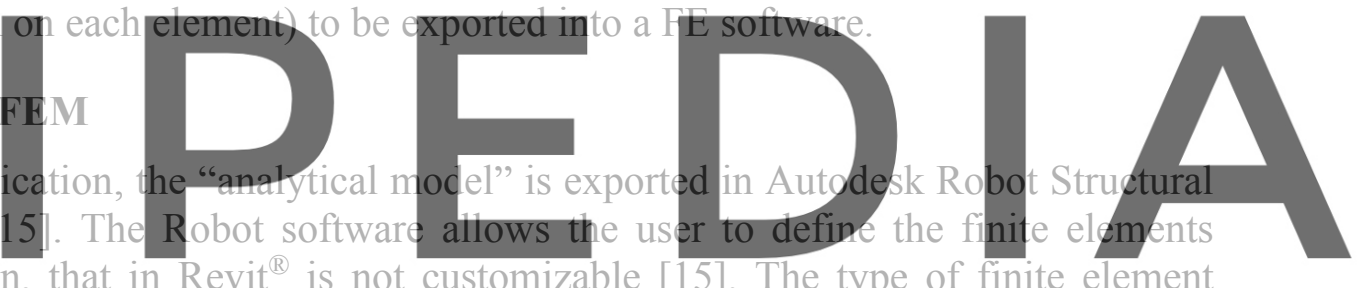

meshing discretization, that in Revit $^{(\mathbb{R})}$ is not customizable [15]. The

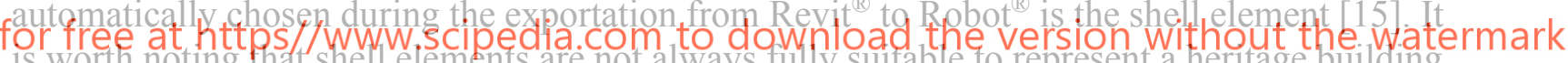
but are appropriate when simplified modeling and preliminary assessment of the structure is needed. On the other hand, the compatibility between the two software codes allows easy updating both architectural and structural models at a later stage [15].

In the FE model, the wall middle planes are represented by thick-shell elements, which are defined as 4-node quadrilateral elements (Q4). The beams are modeled as linear beam elements, with 6 degrees of freedom at each node. Regarding the behavior of Q4 shell elements in connection with beam elements - perpendicular to the plane of finite elements, pinned connections are generated [15]. The selected mesh type is Delaunay, with a $0.2 \mathrm{~m}$ element size. Such a meshing process led the FE model to have 69179 nodes, with 67169 plane elements and 2676 bar elements; the total number of degrees of freedom is 412482 .

\section{FE MODAL ANALYSIS AND PLANNING OF AMBIENT VIBRATION TESTS}

In the structural assessment of historical constructions, linear elastic analysis is always performed, prior to the application of more refined approaches. In establishing the FE model, the following initial assumptions were introduced for the masonry: (a) homogeneous distribution of the masonry elastic properties; (b) the weight per unit volume of the masonry 
and the Poisson's ratio of the masonry were assumed as $18.0 \mathrm{kN} / \mathrm{m}^{3}$ and 0.20 , respectively; (c) the average Young's modulus $E$ was set equal to $1.8 \mathrm{GPa}$. Furthermore, the building foundations were supposed as fixed.

The geometric characteristics of the load-bearing walls and pillars were modeled according to the results of geometric survey and direct inspections: (i) at ground level, the masonry pillars have a thickness of $1.275 \mathrm{~m}$; (ii) at first floor, the masonry walls have a thickness of $0.85 \mathrm{~m}$; (iii) at the upper level, walls are characterized by masonry arches on the façade (Figs. 1-3) and a constant equivalent thickness of $1.20 \mathrm{~m}$ was assumed.

In the lacunar wooden ceilings, the absence of rigid connections between wall-beam and beam-beam elements allows to assume that supports are pinned. The wooden and steel tie beams introduced during the 2012 s interventions were represented in Revit ${ }^{\mathbb{B}}$ according to their geometries and positions and modeled in $\operatorname{Robot}^{\circledR}$ as truss elements.

Selected mode shapes and natural frequencies of the FE model are reported in Fig. 4. As it has to be expected, most of vibration modes involves bending in the transversal direction of the building and the overall structure exhibits a sequence of normal modes similar to the one of a beam supported by springs (Fig. 4).
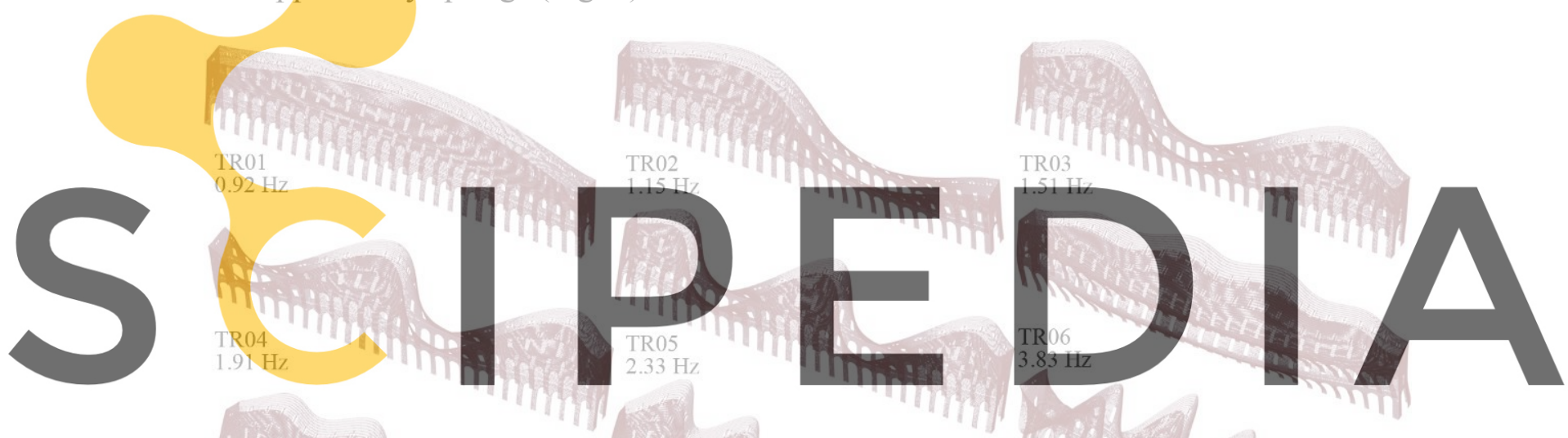

Register for free at https//www.scipedia.com to download the version without the watermark

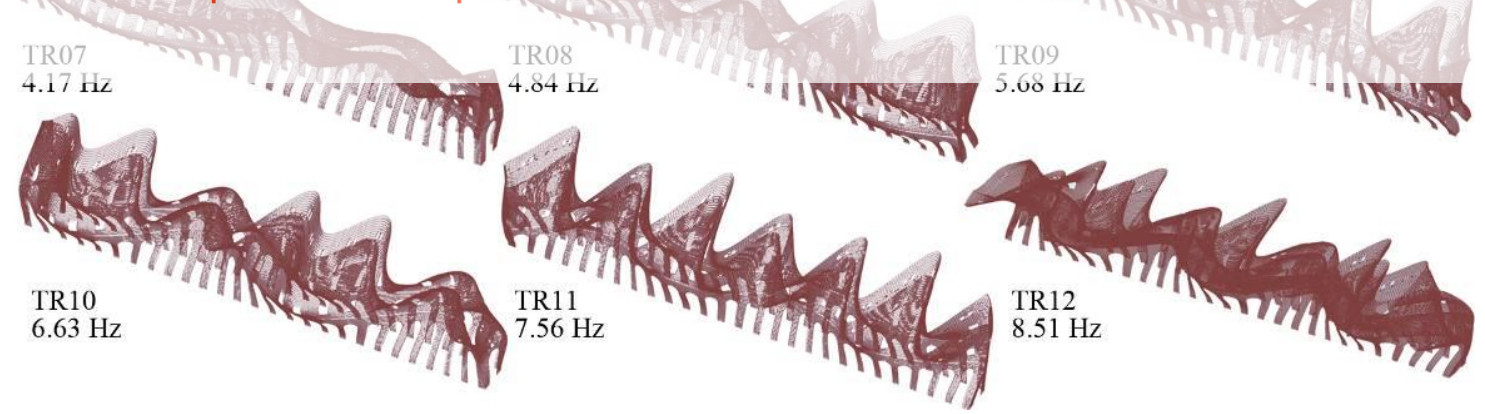

Figure 4. Selected (transverse) vibration modes of the FE model.

\subsection{Ambient Vibration tests and Operation Modal Analysis}

In order to obtain a validation of the FE model and of the adopted H-BIM workflow, ambient vibration tests (AVTs) were performed. The first floor level was extensively instrumented and a series of two set-ups was required to cover the selected 23 measurement points (Fig. 5): 15 accelerometers were used in each set-up and 7 sensors were held stationary as reference transducers (Fig. 5). 
(a)

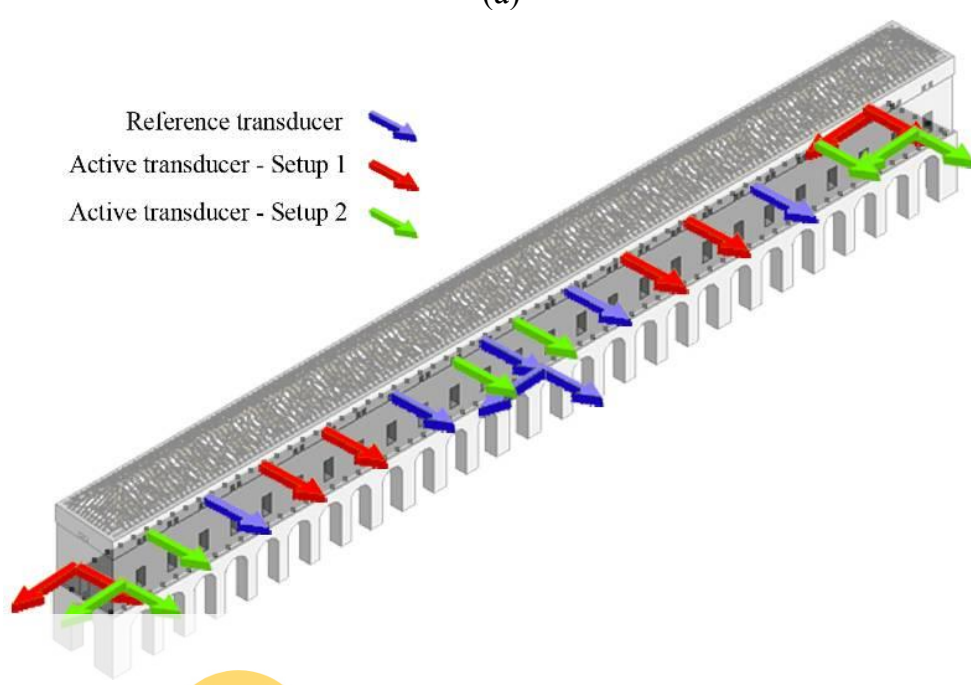

(b)

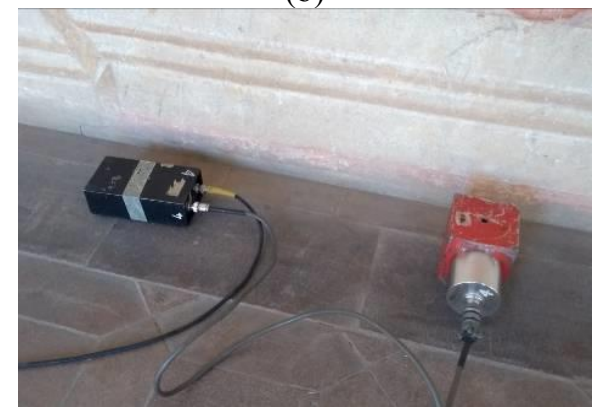

(c)

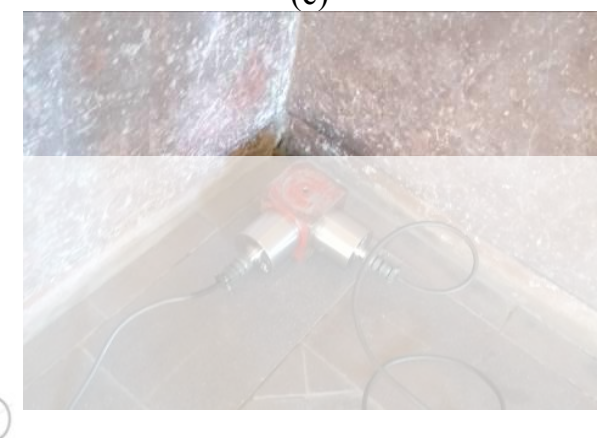

| Reference transducer | Active transducer - Setup 1 | Active transducer - Setup 2

Figure 5. (a) Accelerometers layout and set-ups adopted in ambient vibration tests; Piezoelectric accelerometers
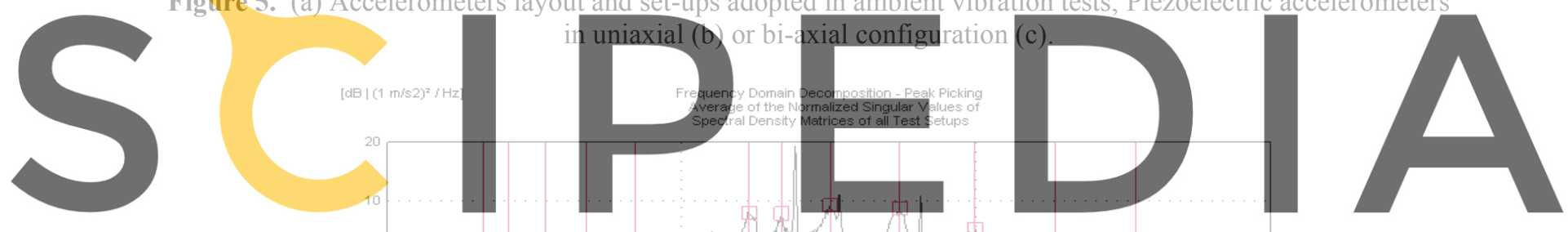

Register for free at https//www.scipedia.com to download the version without the watermark

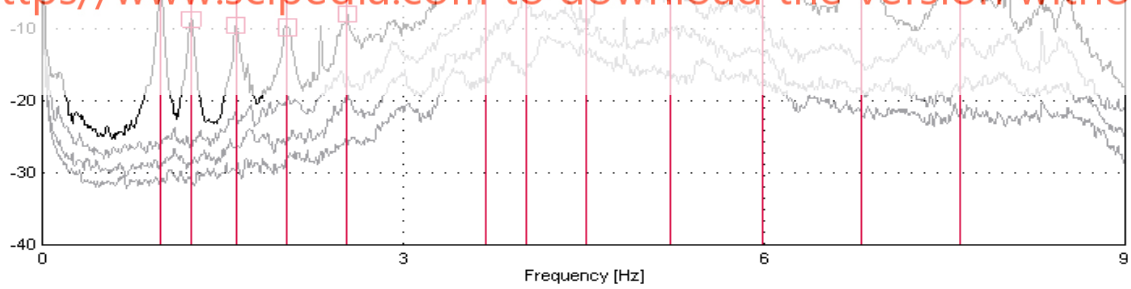

Figure 6. First singular value lines and identification of natural frequencies (FDD).

The AVTs were performed on February 2019 by using the following devices: (i) an acquisition laptop Panasonic Toughbook CF-F9; (b) a multi-channel acquisition system with NI9234 modules (24-bit resolution, $102 \mathrm{~dB}$ dynamic range and anti-aliasing filters); (c) 15 WR731A piezoelectric accelerometers $(10 \mathrm{~V} / \mathrm{g}$ sensitivity and $\pm 0.50 \mathrm{~g}$ of peak acceleration, Figs. 5b and 5c); (d) 15 WR P31 power unit amplifiers (Fig. 5b). The amplifiers were aimed at enhancing the performance of the acquisition chain, providing a constant current to power the internal amplifier, signal amplification and selective filtering. The sampling frequency adopted was equal to $200 \mathrm{~Hz}$, which is more than enough for the investigated building structure whose expected dominant frequencies (Fig. 4) are below $10 \mathrm{~Hz}$. Therefore, low pass filtering and 
decimation were applied to down-sample the data to $40 \mathrm{~Hz}$, obtaining a Nyquist frequency of $20 \mathrm{~Hz}$.

The application of the Frequency Domain Decomposition (FDD) technique [16] implemented in the commercial software ARTeMIS [17] to the collected time series led to the identification of 12 transverse vibration modes in the frequency range of $0-9 \mathrm{~Hz}$. The results of OMA in terms of natural frequencies can be summarized through the plot of Fig. 6, showing the first singular value lines (SV) of the spectral matrix. The inspection of Fig. 6 clearly highlights that the FDD technique provides a clear indication of the building modes through well-defined local maxima in the first SV. The corresponding mode shapes are shown in the upper part of Fig. 7.
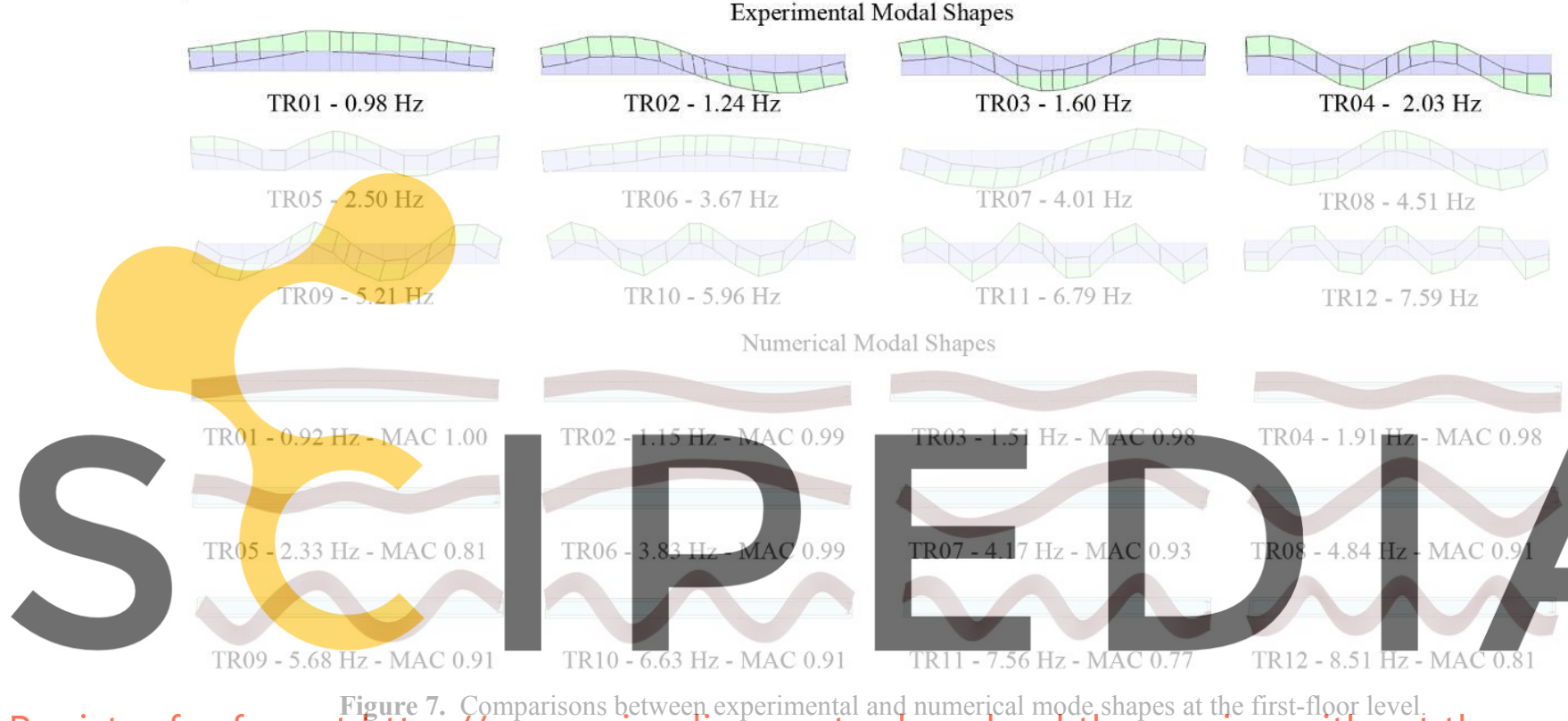

\subsection{Validation of the $\mathbb{F E}$ model and the H-BIIM workflow}

Once the dynamic characteristics of the heritage building were identified through AVT and OMA, a comparison with the FEA results is carried out. As usual, such a comparison is aimed at assessing if the geometric, physical and mechanical assumptions adopted in establishing the FE model have been chosen with a reasonable degree of approximation; on the other hand, since the FE model was implemented through a H-BIM workflow, validating the numerical model also provides a validation of the entire methodology.

The Modal Assurance Criterion (MAC) [18] and the combined frequencies and MAC parameters (FMAC) were used to compare the experimental and numerical modal characteristics. The correlation between the dynamic characteristics of the base FE model and the experimental results is shown in Figs. 7 and 8 . Figure 8 shows imperfect correlation, with frequency discrepancy DF $\left[=100 \cdot\left(f_{\mathrm{FEM}}-f_{\mathrm{EXP}}\right) / f_{\mathrm{EXP}}\right]$ ranging up to about $12 \%$ and an average distance between experimental and natural frequencies of $7.76 \%$. However, the correlation between theoretical and experimental behavior, notwithstanding its roughness, seems to provide a sufficient verification of the model main assumptions (and hence of the whole $\mathrm{H}$ BIM workflow), being a one-to-one correspondence between the mode shapes, with the worst 


\section{MAC value being 0.77 .}

The imperfect correlation between the FE model and the experimental results is conceivably due to the very simplified assumptions on the to the elastic properties of the masonry and should be improved by updating the distribution of the masonry Young's modulus over the building [5-6].

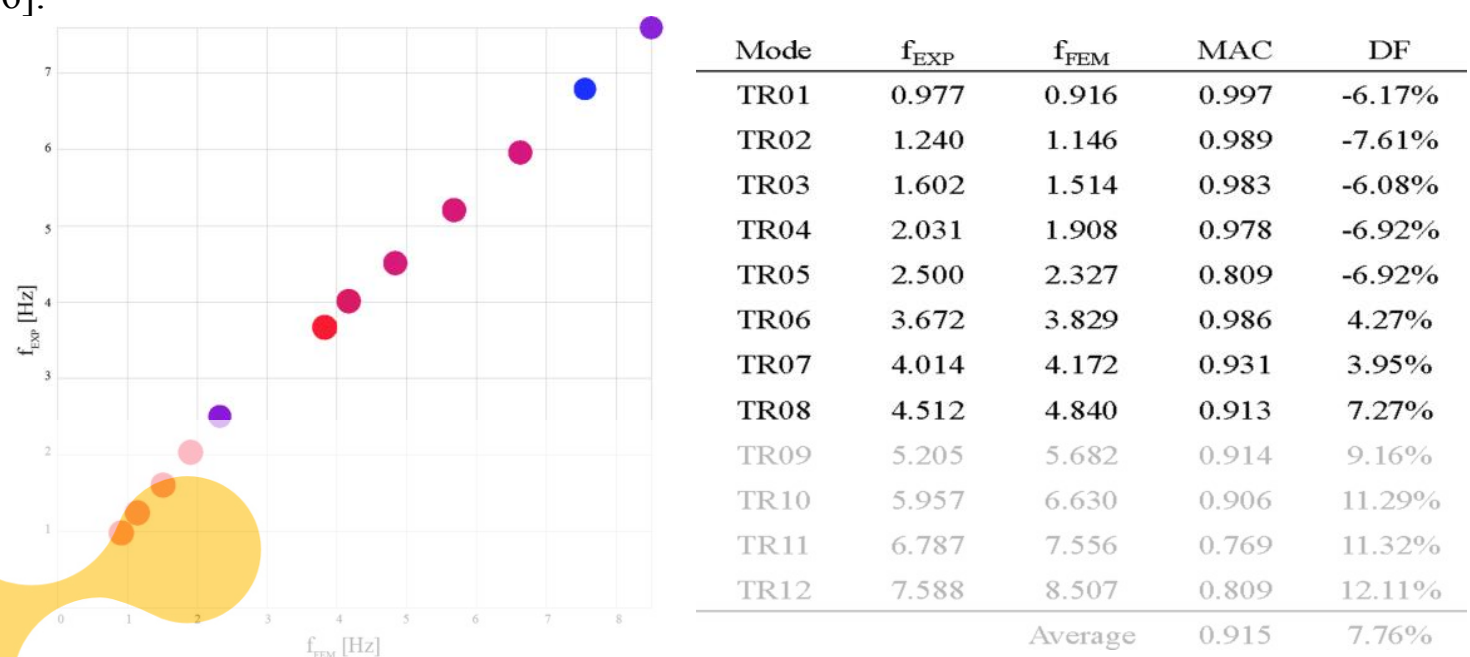

Figure 8. Modal Assurance Criterion (MAC) and frequency discrepancy (DF) between experimental and numerical modes.

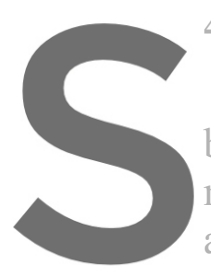

4 CONCLUSIONS

In the paper, the me

by H-BIM and operation

more details, the adop

acquisition from documentary
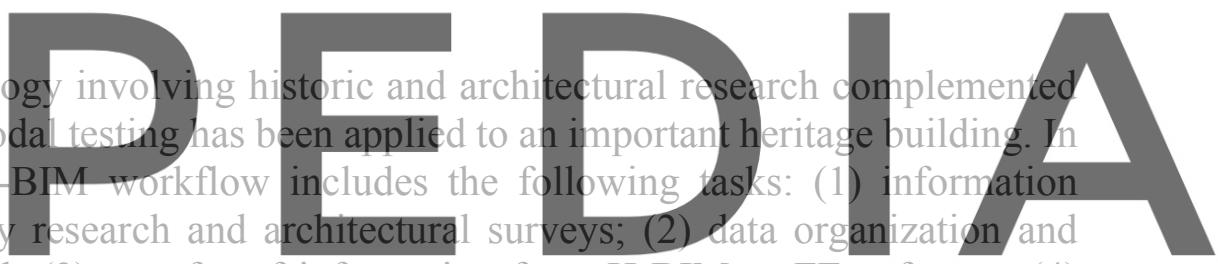

creation of the H-BIM model; (3) transfer of information from H-BIM to FE software; (4)

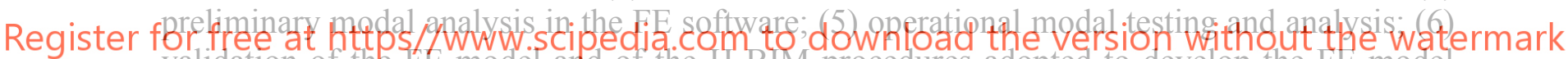
validation of the FE model and of the H-BIM procedures adopted to develop the FE model

through comparison between numerical and experimental modal parameters.

The experience collected in the present investigation allows to draws some conclusions:

- On site inspections, thematic surveys and the comparison of the archive documents with the visual inspection resumed within the H-BIM model improve the knowledge of heritage buildings;

- Dynamic tests in operational conditions provide quantitative parameters (resonant frequencies and mode shapes and damping ratios), which are representative of the structural condition and remarkably contribute to the knowledge of the building. Furthermore, merging the information collected by historic/architectural research, HBIM and dynamic tests should allow to solve the main uncertainties in establishing numerical models and to assess the structural state of preservation of the building in a fully non-destructive way.

\section{REFERENCES}

[1] Binda, L., Saisi, A. and Tiraboschi, C. Investigation procedures for the diagnosis of historic masonries. Constr. Build. Mater. (2000) 14(4): 199-233. 
[2] Italian Ministry for Cultural Heritage. Guidelines for evaluating and mitigation of seismic risk to cultural heritage (in Italian). Gangemi Editore, Rome (1997).

[3] ICOMOS-ISCARASAH. Recommendations for the analysis, conservation and structural restoration of architectural heritage. (2003).

[4] Roca, P., Cervera, M. and Gariup, G. Structural analysis of masonry historical constructions. Classical and advanced approaches. Arch. Comput. Methods Eng. (2010) 17(3): 299-325.

[5] Gentile, C. and Saisi, A. Ambient vibration testing of historic masonry towers for structural identification and damage assessment. Constr. Build. Mater. (2007) 21(6): 1311-1321.

[6] Gentile, C., Saisi, A. and Cabboi, A. Structural identification of a masonry tower based on operational modal analysis. International Journal of Architectural Heritage, (2015) 9(2): 98-110.

[7] Volk, R., Stengel, J. and Schultmann, F. Building Information Modeling (BIM) for existing buildings. Literature review and future needs. Automat. Constr. (2014) 38: 109-127.

[8] Murphy, M., McGovern, E. and Pavia, S. Historic building information modelling (HBIM). Structural Survey (2009) 27(4): 311-327.

[9] Calì, A., Do Valle, Â., and Dias De Moraes, P. Building Information Modeling and Structural Analysis in the Knowledge Path of a Historical Construction. In: R. Aguilar et al. (Eds.): Structural Analysis of Historical Constructions, RILEM Bookseries 18 (2019), pp. 2071-2079.

[10] Barazzetti, L., Banfi, F., Brumana, R., Gusmeroli, G. Previtali, M. and Schiantarelli, G. Cloud-to-BIM-to-FEM: Structural simulation with accurate historic BIM from laser scans. Simul. Model. Pract. Th. (2015) 57: 71-87.

[11] Brumana, R., Della Torre, S., Previtali, M., Barazzetti, L. Cantini, L., Oreni, D. and Banfi, F. Generative HBIM modelling to embody complexity (LOD, LOG, LOA, LOI): surveying, preservation, site intervention - The Basilica di Collemaggio (L'Aquila). Appl. Geomat. (2018) 10(4), 545-567.

[12] Bruno, S., De Fino, M. and Fatiguso, F. Historic Building Information Modelling: performance assessment for diagnosis-aided information modelling and management. Automat. Constr. (2018) 86: 256-276.

[13] Saisi, A. and Terenzoni, S. Galleria degli Antichi and Palazzo Giardino at Sabbioneta: Remarks from archive research and direct survey. In: G. Milani et al. (Eds.): 10th International Masonry Conference, International Masonry Society (2018), pp. 907-916.

[14] Dal Barco, G., Perobelli, S. and Sartor T. Palazzo del Giardino e Galleria degli Antichi a Sabbioneta. MSc Thesis, Politecnico di Milano, Milan, Italy (2016).

[15] Autodesk Inc. Integrating Revit Structure and Robot Structural Analysis Professional Workflows (2010).

[16] Brincker, R., Zhang, L. and Andersen, P. Modal identification of output-only systems using frequency domain decomposition. Smart Mater. Struct. (2001) 10(3):441-445.

[17] Structural Vibration Solutions (SVS). ARTeMIS Extractor 2010. Aalborg, Denmark (2010).

[18] Allemang, R.J. and Brown, D.L. Correlation coefficient for modal vector analysis. In: Proceedings 1st International Modal Analysis Conference (1983), pp. 110-116. 